\title{
CHARACTERIZATION OF COMPLEX WATER VAPOUR FIELD STRUCTURES AND THEIR GENESIS BASED ON THE COMBINED USE OF RAMAN LIDAR MEASUREMENTS AND MESO-NH MODEL SIMULATIONS
}

\author{
Paolo Di Girolamo ${ }^{1^{*}}$, Marie-Noelle Bouin ${ }^{2}$ \\ ${ }^{1}$ Scuola di Ingegneria, Università della Basilicata, Potenza, Italy \\ ${ }^{2}$ Météo-France/CNRM, 29280 Plouzané, France \\ *Email:paolo.digirolamo@unibas.it
}

\begin{abstract}
As part of the Cevennes-Vivarais site, the University of Basilicata Raman lidar system (BASIL) was deployed in Candillargues throughout the duration of HyMeX-SOP 1 (September-November 2012), providing highresolution and accurate measurements, both in daytime and night-time, of atmospheric temperature, water vapour mixing ratio and particle backscattering and extinction coefficient at three wavelengths. Measurements carried out by BASIL on 28 September 2012 reveal a quite complex vertical structure of the water vapor field. Reported Raman lidar measurements were run in the time interval between two consecutive heavy precipitation events, from 15:30 UTC on 28 September to 03:30 UTC on 29 September 2012. Throughout most of this observation period, lidar measurements reveal the presence of four distinct humidity layers.

The present research effort aims at assessing the origin of the different humidity filaments observed by BASIL on this day. The analysis relies on the comparisons between Raman lidar MESO-NH model simulations. Back-trajectory analyses from the model reveal that air masses ending in Candillargues at different altitudes levels are coming from different geographical regions. Specifically, the analysis reveals that air masses within the surface humidity layer were originated over the Atlantic Ocean, while air masses within the elevated filamentary humidity layer, also coming from the Atlantic Ocean, overpassed the sea stretch North of Spain and Southern France at an altitude of $\sim 1 \mathrm{~km}$. In addition, air masses within the lower of the two upper layers are found to overpass Southern Spain and Marocco, descending from an elevation of 2$3.5 \mathrm{~km}$, while air masses within the uppermost
\end{abstract}

layer are found to overpass Algeria, descending from an elevation of 3.5-5 km.

\section{HyMeX-SOP1}

HyMeX was conceived with the goal of improving the comprehension of the water cycle in the Mediterranean [1]. Within this program a major field campaign, named Special Observation Period 1 (SOP1), took place in the period September-November 2012 over the northwestern Mediterranean Sea and its surrounding coastal regions in France, Italy and Spain, with a specific focus on the study of heavy precipitation and flashflood events $[2,3]$.

As part of the Cévennes-Vivarais observational site, a set of research instruments was installed in an atmospheric 'supersite' located in Candillargues $\left(43^{\circ} 37^{\prime} \mathrm{N}, 4^{\circ} 04^{\prime} \mathrm{E}\right.$, elevation: $\left.1 \mathrm{~m}\right)$, near the coast and south of the Massif Central. Among these instruments, a wind profiler, a radiometer, a radiosonde launching facility and a variety of radars and lidars (BASIL being one of these) were present.

\section{BASIL}

BASIL operated from 5 September to 5 November 2012, collecting more than $600 \mathrm{~h}$ of measurements, distributed over 51 measurement days and 19 Intensive Observation Periods (IOPs). BASIL uses a tripled Nd:YAG laser (single pulse energy power at $355 \mathrm{~nm}: 500 \mathrm{~mJ}$, pulse repetition frequency: $20 \mathrm{~Hz}$, average power: $10 \mathrm{~W}$ ) and a Newtonian telescope (primary mirror diameter: 45 $\mathrm{cm}, \mathrm{f} / 2.1)$. The major feature of BASIL is represented by its capability to perform highresolution and accurate measurements of atmospheric temperature and water vapour, both in daytime and night-time, based on the application of the rotational and vibrational Raman lidar techniques in the ultraviolet [3-6]. Besides temperature and water vapour, BASIL is 
also capable of providing measurements of particle backscatter at 355, 532 and $1064 \mathrm{~nm}$, particle extinction at 355 and $532 \mathrm{~nm}$, and particle depolarization at 355 and $532 \mathrm{~nm}$ [7-10]).

\section{RESULTS}

\subsection{Lidar measurements}

Raman lidar measurements considered in this research effort were run in the time interval between two consecutive heavy precipitation events, from 15:30 UTC on 28 September to 03:30 UTC on 29 September 2012. Figure 1 illustrates the time evolution of the rangecorrected signal at $1064 \mathrm{~nm}$ as measured by BASIL over this time interval. The figure reveals the presence throughout most of the observational period of stratiform clouds around $4 \mathrm{~km}$, with a very limited vertical extent $(\sim 0.5 \mathrm{~km})$. Stratiform rain events are found to take place between 18:30 and 20:00 UTC on 28 September and between 00:30 and 03:30 UTC on 29 September 2019. One of these events, between 15:30 and 16:30 UTC on 28 September, appears in the form of Virga, with precipitating particles sublimating before reaching the ground. In this time interval, a lidar dark band is also observed at $\sim 3.4 \mathrm{~km}$, this phenomenon being associated with the variable scattering properties of melting hydrometeors in the snow flake to rain conversion process $[10,11,12]$.

Figure 2 illustrates the time evolution of water vapour mixing ratio, $\mathrm{m}_{\mathrm{H} 2 \mathrm{O}}$, as measured by BASIL over the same time period considered in Figure 1. This figure reveals the presence throughout most of the observation period of four distinct humidity layers: a surface layer extending up to $0.4-0.8 \mathrm{~km}$ a.s.l.; a filamentary structure, first observed around 17:30 UTC, with a progressively descending trend from $\sim 1 \mathrm{~km}$ down to $\sim 0.5 \mathrm{~km}$ and a variable vertical extent within the range 0.1$0.4 \mathrm{~km}$; two upper humid layers, one extending from $1.3-1.5 \mathrm{~km}$ to $2.4-2.8 \mathrm{~km}$, with values of $\mathrm{m}_{\mathrm{H} 2 \mathrm{O}}$ up to $7.5 \mathrm{~g} \mathrm{~kg}^{-1}$, and one above extending up to approx. $4 \mathrm{~km}$, with values of $m_{\mathrm{H} 2 \mathrm{O}}$ not exceeding $6 \mathrm{~g} \mathrm{~kg}^{-1}$. Relatively high values of $\mathrm{m}_{\mathrm{H} 2 \mathrm{O}}$ are observed throughout most part of the troposphere, with a residual value of $3 \mathrm{~g} \mathrm{~kg}^{-1}$ around $6 \mathrm{~km}$.

\subsection{Model simulations and back-trajectory analysis}

For the purpose of this analysis the nonhydrostatic numerical research model MESO-NH was run over a $1446 \times 1778 \mathrm{~km}^{2}$ domain $\left(35^{\circ}-48^{\circ}\right.$ $\mathrm{N}, 8^{\circ} \mathrm{W}-16^{\circ} \mathrm{E}$ ), with a horizontal resolution of $2.5 \mathrm{~km}$. Atmospheric forcing are taken from AROME-WMED. The considered MESO-NH simulation started at 00:00 UTC on 27 September and ended at 00:00 UTC on 29 September 2012.

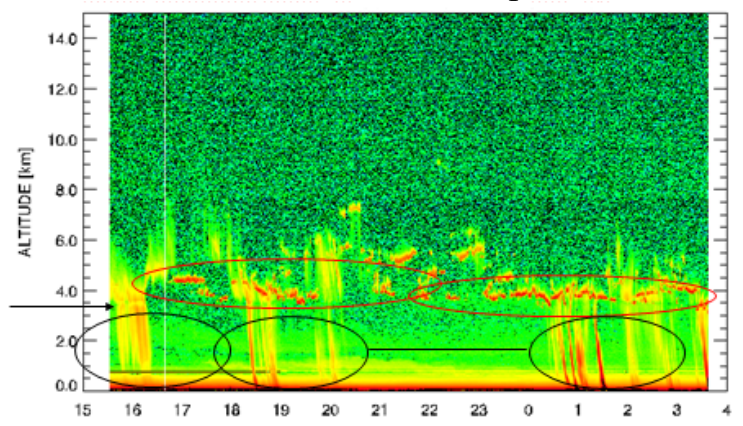

Figure 1: Time evolution of the range-corrected signal at $1064 \mathrm{~nm}$ (expressed in arbitrary units) as measured by BASIL over this time interval from 15:30 UTC on 28 September to 03:30 UTC on 29 September 2012. The red ellipses indicate the stratiform clouds, the red ellipses indicate the stratiform rain events, while the black arrow on the left portion of the figure reveal the presence of a dark band event.

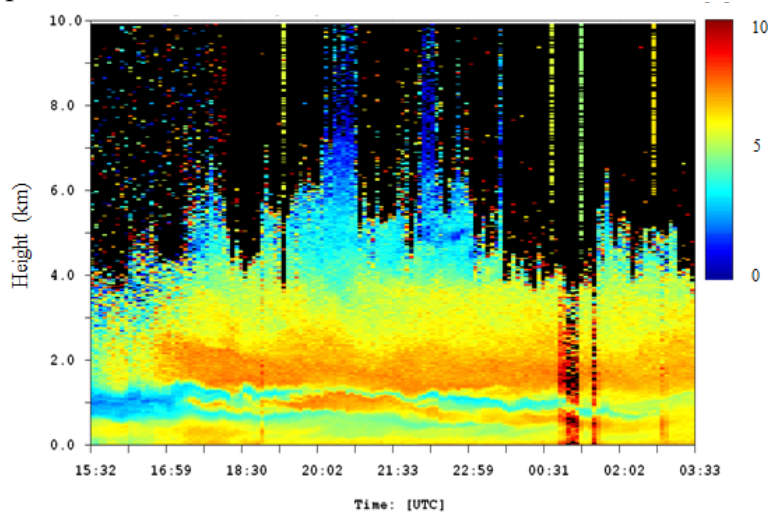

Figure 2: Time evolution of $\mathrm{m}_{\mathrm{H} 2 \mathrm{O}}$ as measured by BASIL over the same time period considered in Fig. 1. Thus, back-trajectories can be extended back in time by 48 hours. Figure 3 illustrates the comparison between BASIL measurements and MESO-NH simulations in the time interval from 15:30-23:30 UTC on 28 September 2012. The four different humidity layers present in the Raman lidar measurements are well reproduced by Meso-NH, both in terms of timing of occurrence and mixing ratio values, with the only exception of the mixing ratio values within the elevated filamentary structure, with measured values not exceeding $7 \mathrm{~g} \mathrm{~kg}^{-1}$ and simulated values being as large as $8-9 \mathrm{~g} \mathrm{~kg}^{-1}$. 


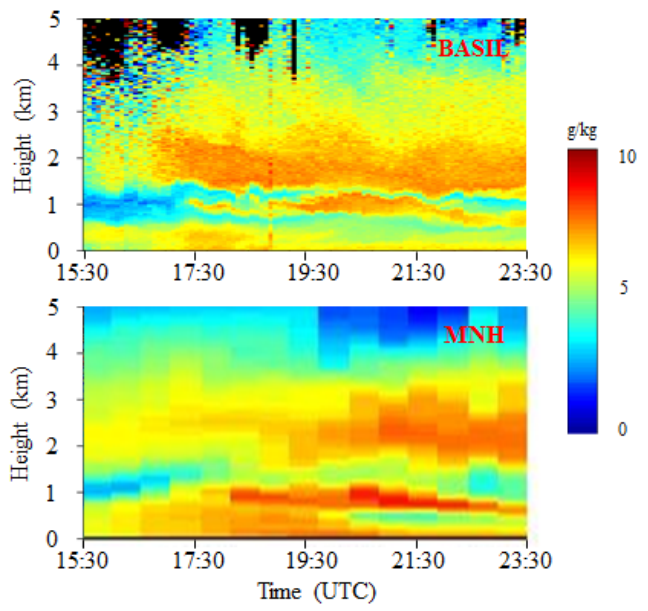

Figure 3: Time evolution of $\mathrm{m}_{\mathrm{H} 2 \mathrm{O}}$ as measured by BASIL (upper panel) and simulated by MESO-NH (lower panel).

An assessment of the origin of the different humidity layers observed by the Raman lidar on this day is also carried out based on the use of MESO-NH simulated data. Back-trajectory analyses from this model allow revealing that air masses reaching Candillargues at different altitudes levels are coming from different geographical regions. Figure 4 illustrates the $48 \mathrm{~h}-$ backtrajectory analysis for the air masses ending in Candillargues at 15:30 UTC on 28 September 2012. The trajectory colors identify the altitude experienced by the air masses during their transport to Candillargues, while the numbers at the beginning of each trajectory identify the air masses ending altitude in Candillargues. The red ellipse in the figure highlights the backtrajectories of the air masses ending in Candillargues within the surface humidity layer. The analysis reveals that air masses within this layer were originated over the Atlantic Ocean. Figure 5 illustrates the 48h-backtrajectory analysis of the air masses ending in Candillargues at 18:00 UTC on 28 September 2012. The red ellipses identify the back-trajectories ending at the altitude of elevated filamentary humidity layer and within the two upper layers. The figure reveals that air masses within the elevated filamentary humidity layer are also coming from the Atlantic Ocean, overpassing the sea stretch North of Spain and Southern France at an altitude of $\sim 1 \mathrm{~km}$. The figure also shows that air masses within the lower of the two upper layers overpassed Southern Spain and Marocco, descending from an elevation of 2-3.5 km, while air masses within the uppermost layer overpassed Algeria, descending from an elevation of $3.5-5 \mathrm{~km}$.

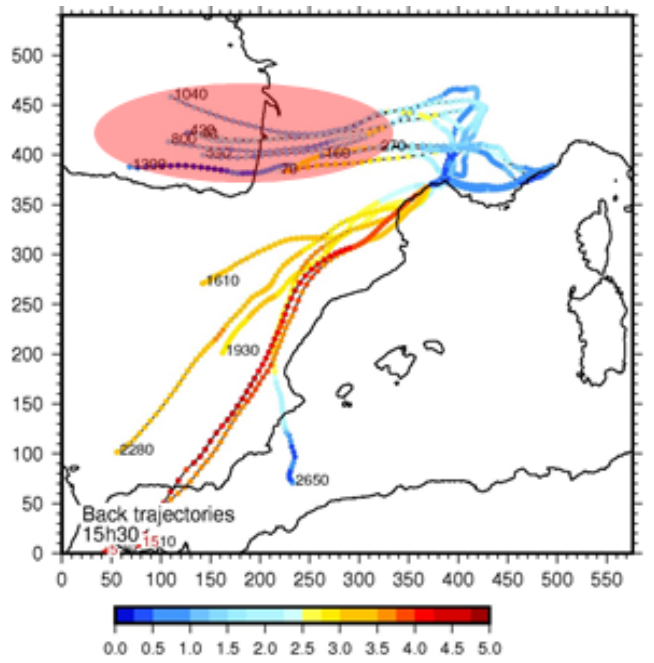

Figure 4: $48 \mathrm{~h}$ back-trajectory ending in Candillargues at 15:30 UTC on 28 September 2012 as simulated by MESO-NH. Colors identify the altitude of the air masses during their transport to Candillargues, with the color legend being expressed in $\mathrm{km}$. Numbers at the beginning of each trajectory identify the ending altitude in Candillargues. Red ellipse: back-trajectories ending in Candillargues within the surface humidity layer.

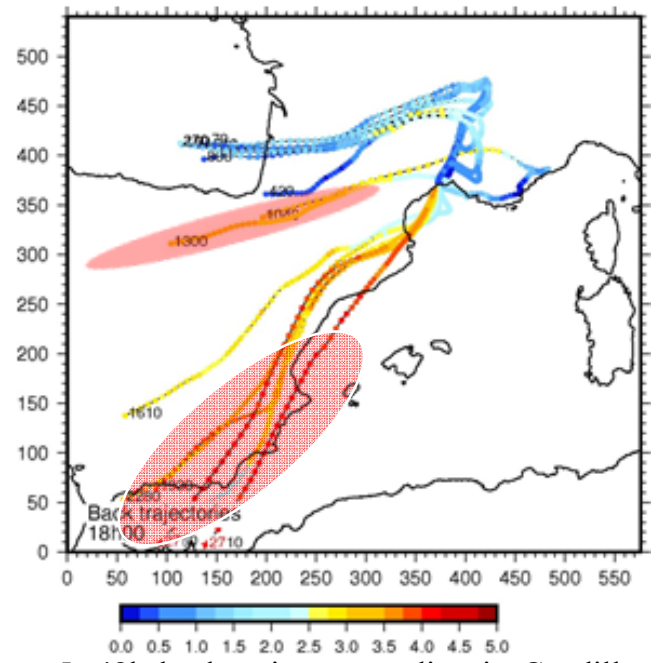

Figure 5: $48 \mathrm{~h}$ back-trajectory ending in Candillargues at 18:00 UTC on 28 September 2012 as simulated by MESO-NH. Red ellipses: back-trajectories ending in Candillargues at the altitude of elevated filamentary humidity layer and within the two upper layers.

Back-trajectory analysis ending in Candillargues at 18:00 UTC on 28 September 2012 and starting 240 hours (10 days) earlier at 18:00 UTC on 18 September 2012 have also been determined through the application of the NOAA HYSPLIT 
Lagrangian back-trajectory model [13]. The backtrajectory analysis extending back in time by 10 days reveals that air masses in the uppermost humid layer are originated over the Saharan desert in Central Africa (Mali).

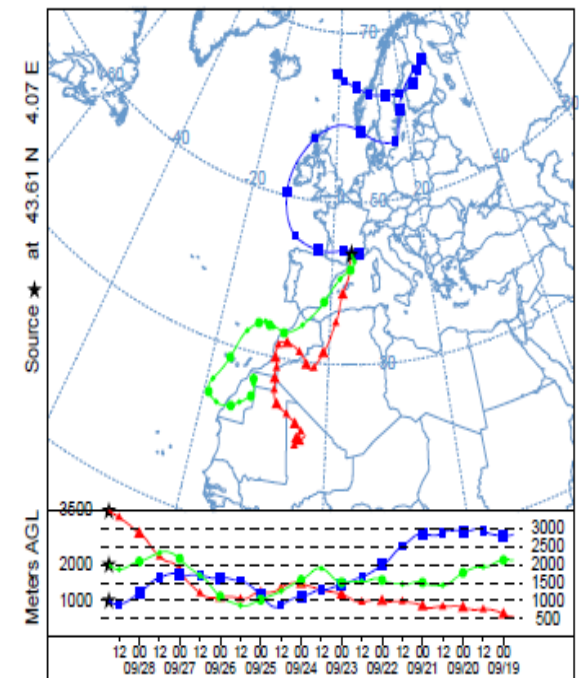

Figure 6: $240 \mathrm{~h}$ back-trajectory ending in Candillargues at 18:00 UTC on 28 September 2012 as simulated by NOAA-HYSPLIT back-trajectory model.

As a continuation of this research effort, we intend to investigate more precisely the origin of the sounded air parcels and their possible modifications along their route, also referring to the time series of potential temperature and other relevant parameters, as the aerosol properties.

\section{ACKNOWLEDGEMENTS}

This work was supported by the Italian Ministry for Education, University and Research under the Grant OT4CLIMA. The authors gratefully acknowledge NOAA Air Resources Laboratory for the use of the HYSPLIT transport and dispersion model.

\section{REFERENCES}

[1] P. Drobinski et al., HyMeX, a 10-year multidisciplinary program on the Mediterranean water cycle, Bull. Am. Meteorol. Soc. 95: 1063-1082, doi: 10.1175/BAMS-D-12-00242.1 (2014).

[2] V. Ducrocq et al., HyMeX-SOP1, the field campaign dedicated to heavy precipitation and flashflooding in northwestern Mediterranean, Bull. Am. Meteorol. Soc. 95: 1083-1100, doi: 10.1175/BAMS-D12-00244.1 (2014).

[3] F. Duffourg et al., Offshore deep convection initiation and maintenance during HyMeX IOP 16a heavy precipitation event, Quarterly Journal of the
Royal Meteorological Society 142 (Suppl 1): 259-274, doi: 10.1002/qj.2725 (2016).

[4] Di Girolamo et al., Rotational Raman lidar measurements of atmospheric temperature in theUV, Geophys. Res. Lett. 31: L01106, doi: 10.1029/2003GL018342 (2004).

[5] Di Girolamo P, Behrendt A, Wulfmeyer V., Spaceborne profiling of atmospheric temperature and particle extinction with pure rotational Raman lidar and of relative humidity in combination with differential absorption lidar: performance simulations, Appl. Opt. 45: 2474-2494, doi: 10.1364/AO.45.002474 (2006).

[6] P. Di Girolamo et al., Multiparameter Raman lidar measurements for the characterization of a dry stratospheric intrusion event, J. Atmos. Oceanic Technol. 26: 1742-1762, doi: 10.1175/2009JTECHA1253.1 (2009).

[7] Bhawar et al., The water vapour intercomparison effort in the framework of the Convective and Orographically-induced Precipitation Study: Airborneto-ground-based and airborne-to-airborne lidar systems, Q. J. R. Meteorol. Soc. 137: 325-348, doi: 10.1002/qj.697 (2011).

[8] V. Griaznov et al., Spatial Distribution of Doubly Scattered Polarized Laser Radiation in the Focal Plane of a Lidar Receiver, Applied Optics 46, 6821-6830, doi: 10.1364/AO.46.006821 (2007).

[9] P. Di Girolamo et al., UV Raman Lidar measurements of relative humidity for the characterization of cirrus cloud microphysical properties, Atmospheric ChemistrY and Physics 9, 8799-8811, doi: 10.5194/acp-9-8799-2009 (2009).

[10] P. Di Girolamo et al., Raman Lidar observations of a Saharan dust outbreak event: Characterization of the dust optical properties and determination of particle size and microphysical parameters, Atmospheric Environment 50, 66-78 (2012).

[11] P. Di Girolamo et al., Lidar and radar measurements of the melting layer: observations of dark and bright band phenomena, Atmospheric Chemistry and Physics 12, 4143-4157, doi: 10.5194/acp-12-4143-2012 (2012).

[12] P. Di Girolamo et al., Model simulations of melting hydrometeors: a new Lidar bright band from melting frozen drops, Geophysical Research Letters 30, doi: 10.1029/2002GL016825 (2003).

[13] V. Griaznov et al., Numerical Simulation of Light Backscattering by Spheres With Off-Center Inclusion. Application for Lidar Case, Applied Optics 43, 55125522, doi: 10.1364/AO.43.005512.

[14] Draxler, R. R and Hess, G. D.: An overview of the HYSPLIT_4 modeling system for trajectories, dispersion and deposition, Australian Meteorological Magazine 47(4), 295-308 (1998). 